\title{
MUSEU DE ARTE, INCLUSÃO DA PESSOA CEGA, DESAFIOS DO EDUCATIVO ${ }^{1}$
}

\author{
Profa. Dra. Maria Cristina da Rosa Fonseca da Silva ${ }^{2}$ \\ Adriane Cristine Kirst ${ }^{3}$
}

\begin{abstract}
Resumo: Este artigo sistematiza a investigação realizada no projeto Museu de artes: possibilidades de inclusão. Esse projeto se propôs a investigar os caminhos de inclusão da pessoa cega no espaço museológico. O projeto foi desenvolvido junto ao setor educativo em parceria com a UDESC, buscando identificar os processos de interação cego - museu de arte, por meio do uso de materiais e tecnologias acessíveis que possibilitem ao cego uma interação com a obra de arte nesse espaço.
\end{abstract}

Palavras Chave: Inclusão - Museu de arte - Objetos Pedagógicos

\section{O museu como instituição pública:}

Observamos que por meio de trocas de conhecimento entre a universidade e o museu, desenvolveu-se uma investigação e produção de materiais adaptados para o público cego. Essa atividade criou bases teórico-práticas que possibilitam a pessoa cega aproximar-se do patrimônio histórico cultural que a cidade oferece, bem como também possibilita ao professor de artes dispor de mais uma ferramenta para trabalhar a inclusão. Frisando que na maioria das vezes, o profissional tem estudantes com necessidades especiais em suas turmas, mas, não possui um preparo adequado para abordar assuntos e propor experiências que tenham significado para toda a classe.

O Projeto Museu de Artes: possibilidades de inclusão, é um dos projetos vinculado ao Laboratório de Educação Inclusiva da Universidade do Estado de Santa Catarina LEDI/UDESC e tem parceria com o Museu de Artes de Santa Catarina - MASC, Associação de Atendimento e Integração à Criança Deficiente Visual Manoela Bastos Silva AAMABAS. A pesquisa foi realizada utilizando-se de uma metodologia de pesquisa-ação, fundamentada por meio da bibliografia encontrada sobre o assunto, consultoria da professora doutora Amanda Tojal da Pinacoteca de São Paulo e relatos de pessoas cegas que utilizaram as matrizes táteis. Destaca-se que o Projeto é pioneiro na inclusão de pessoas cegas a partir de materiais adaptados em Museus de Arte de Santa Catarina.

\footnotetext{
${ }^{1}$ Projeto Museu de Arte: possibilidades de inclusão.

${ }^{2}$ Orientadora do projeto -Profa.do CEAD e do PPGAV - CEART/UDESC.

${ }^{3}$ Estudante de Arte - CEART/UDESC e membro do grupo de pesquisa: Educação, Arte e Inclusão do CNPq.
} 
Segundo a definição de Museu do ICOM (International Council of Museums) ${ }^{4}$, o museu é uma instituição aberta ao público em geral onde nenhuma restrição pode ser imposta a nenhum tipo de visitante. Assim, raça, cor, religião, afiliação político-partidária, idade ou condição física e/ou mental não podem ser empecilhos para qualquer visitante. No que diz respeito à infra-estrutura arquitetônica, a acessibilidade se mostra como algo concreto, tornando-se claro os pontos a serem adaptados. Quando pensamos na acessibilidade às obras de arte para pessoas cegas, muitas são as dificuldades a serem vencidas. Ao penetramos no espaço de um museu, uma das primeiras coisas que sabemos é que não se pode tocar nas obras de arte, com exceção de trabalhos contemporâneos cuja interação faz parte da poética do artista. O desafio imposto ao projeto é o de tornar estas obras que não podem ser tocadas acessíveis aos cegos.

O Museu de Arte de Santa Catarina - MASC, através do Núcleo de Arte Educação esteve aberto a todas as etapas do projeto dividindo as experiências desenvolvidas. Primeiramente, procuramos investigar a ação do museu para poder compreender seu papel na sociedade. A importância do espaço do museu, por se tratar de uma instituição de interesse público e patrimonial, possibilitou a investigação do processo de interação do cego com o objeto artístico. Pensar o museu como um espaço que proporcione experiências significativas ao público cego significa reconhecer a necessidade de criação de mecanismos e tecnologias que estabeleçam contato maior com a obra de arte. Outro aspecto relevante é a possibilidade de instrumentalizar o professor de arte para uma cultura de inclusão de seus estudantes. Neste sentido, buscamos dados que diagnosticassem o trabalho desenvolvido por outras instituições quanto ao quesito 'acessibilidade do sujeito cego nos museus'.

Os grandes museus ao redor do mundo vêm desenvolvendo trabalhos que possibilitem uma maior aproximação do sujeito cego com as obras de arte. A maioria oferece ao visitante etiquetas em Braille e áudio-guias como algumas das soluções encontradas, mas outras instituições também possibilitam visitas guiadas e matrizes táteis que são desenvolvidas a fim de que se possa de fato tocar e conhecer obras de artes que não seriam possíveis sem o material de apoio. Outros vão um pouco mais além, como é o caso da Tate Modern em Londres que disponibiliza em seu site um recurso on-line, por meio do qual as pessoas com baixa visão podem apreciar algumas obras do acervo em close e montando-se passo a passo na tela do computador. Para os cegos a descrição de quadros, explicações sobre

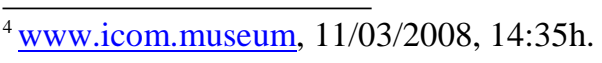


o artista e período da história da arte estão disponíveis em áudio ${ }^{5}$. No Brasil, a Pinacoteca ${ }^{6}$ de São Paulo vem desenvolvendo um sério trabalho com deficientes visuais, disponibilizando aos visitantes matrizes táteis, maquetes do prédio e também de algumas obras, juntamente com a mediação feita pelos profissionais do museu. Este trabalho na Pinacoteca contou com a experiência de Amanda Tojal que iniciou a experiência junto ao MAC, Museu de Arte Contemporânea da USP.

Outro ponto importante levantado pelo projeto é a inclusão do estudante cego na escola, pois sabemos das dificuldades enfrentadas tanto pelo referido estudante, quanto pelo professor de Arte que muitas vezes não tem um preparo adequado para uma inclusão de fato, e que muitas vezes possui mais de um estudante com necessidades especiais em suas turmas, nesses casos o museu torna-se um espaço de possibilidades de ampliação da cidadania.

\section{Museu e Escola, uma parceria inclusiva:}

A fim de entender melhor as questões que envolvem a inclusão, relembramos um pouco a história da humanidade e vemos que segundo Mendes (2006) foi no século XVI que se começou a pensar na educação de alunos especiais, sendo que naquela época a solução encontrada foi a segregação e o confinamento das pessoas ditas diferentes em asilos e manicômios. Essa prática se dava não só para protegê-los, mas principalmente, para proteger a sociedade de então. Somente no século XIX começaram a ser abertas as primeiras turmas para os alunos ditos "difíceis" em escolas regulares.

Entretanto hoje, muito lentamente, a maneira de olhar para as pessoas com necessidades especiais vem mudando, pois sempre se acreditou que ao separar essas pessoas dos demais estudantes, elas seriam mais bem atendidas. Porém esse não é o pensamento atual. Vygotsky, em seu texto sobre a defectologia (1924), já apontava a importância da interação social para a aprendizagem.

Com as transformações políticas e sociais na realidade brasileira que começaram a ser marcadas a partir da década de 60 , as minorias passaram a serem vistas de outra forma, tanto as mulheres, quanto os negros, os gays e, é claro, também as pessoas com deficiências, sejam elas físicas ou mentais que passaram a ser mais ouvidas. As pessoas com deficiência conquistaram, nos últimos anos, a responsabilidade de protagonizar a sua história e as suas lutas. Esse movimento possibilitou uma participação maior dessas minorias na comunidade.

\footnotetext{
${ }^{5}$ www.tate.org.uk, 22/02/2008, 9:10h.

${ }_{6}^{6}$ Palestra da Profa. Dra. Amanda Tojal no Encontro do Grupo de Pesquisa: Educação, Arte e Inclusão da UDESC.
} 
A inclusão dos estudantes com necessidades especiais, e aqui no caso o cego, traz benefícios tanto para este, quanto para os demais estudantes. Para Mendes (2006), por meio da inclusão escolar, o estudante especial teria mais desafios; em aprender e observar outras crianças no convívio diário da sala de aula; já para o estudante sem deficiência essa integração dá abertura para uma maior aceitação das diferenças e limites, tanto dos colegas quanto de si próprios.

Por essa razão tanto o museu, quanto a escola e o professor de artes, estão diante de uma transformação que se faz necessária: ampliar as possibilidades de acesso de outros públicos ao museu. Neste ponto, parece importante salientar que as conquistas mencionadas acima foram alcançadas porque houve uma conexão entre pais, pesquisadores, pessoas com deficiência, prestadores de serviço e políticos (devido ao custo elevado das escolas especiais $^{7}$ ).

A integração das pessoas com necessidades especiais ganhou força em todo o mundo a partir dos anos 80 e portadores de deficiência hoje têm conquistado oportunidades, incluindo a defesa de seus direitos. Leontiev (2004) aponta a importância de se levar em conta o fato de que cada ser humano é diferente, e que mediante condições adequadas e métodos de ensino especiais muitas, das deficiências podem praticamente sumir diante de experiências que se proponham a dar condições de aprendizagem igualitária para todos. Portanto, o desenvolvimento depende das condições que são dadas a esses estudantes. Se olharmos para trás, com certeza muita coisa melhorou no que diz respeito a acessibilidade, entretanto, ainda estamos longe de uma verdadeira inclusão, pois não basta ao estudante especial estar dentro do espaço físico da sala de aula, ou do museu; mas, para ser de fato incluído, o cego deve estar participando das mesmas atividades e interagindo com os demais colegas.

Por isso, quando pensamos na realidade brasileira, percebemos que a grande maioria das pessoas com necessidades especiais ainda estão fora de qualquer tipo de instituição educacional. Já as que estão inseridas nesse contexto ainda encontram professores despreparados para atender as suas necessidades, em conseqüiência dos limites da formação acadêmica $^{8}$, do pouco material e recursos tecnológicos de apoio e dos péssimos salários, que tornam esses profissionais desmotivados e apáticos diante de novos desafios. Por outro lado, há o descaso do poder público que é evidente, mesmo assim, houve um interesse econômico para que a inclusão fosse posta em prática, ou pelo menos no papel. Mas não basta termos

\footnotetext{
${ }^{7}$ Acredita-se que muitas vezes a legislação parece estabelecer-se de forma casuística, privilegiando os interesse políticos acima dos sociais, neste caso, os políticos aderem ao projeto da escola inclusiva para diminuir os custos do estado.

${ }^{8}$ A grande maioria das licenciaturas não contemplam uma disciplina de inclusão em suas matrizes curriculares.
} 
leis que incluam. A inclusão de qualidade se dá na prática do dia-a-dia, dentro da sala de aula, na relação professor- aluno, ou dentro de um museu que esteja preparado para atender este público. É de suma importância, que os debates não sejam só utópicos, mas que dêem conta de uma nova realidade. A política de inclusão, portanto é algo muito recente, e é preciso um preparo que também deve partir dos profissionais de educação, tanto os que atuam em sala de aula quanto os que atuam no museu.

\section{O lúdico no museu de arte:}

O museu de arte apresenta condições de configurar-se como um espaço criativo no qual o lúdico pode ser resgatado, recriado, reinventado. Em parcerias, com outras áreas, tirando o cego do espaço restrito e protegido da sua casa ou até sala de aula. Fortuna ${ }^{9}$ nos fala da importância do ato de brincar, nestes termos:

\footnotetext{
Brincar ou jogar (não importa, aqui, distinguir estes termos, senão captar o sentido que tem em comum) é uma atividade fundamental no ser humano, a começar porque funda o ser humano em nós: aquilo que define o ser humano - inteligência, criatividade, simbolismo, emoção e imaginação, para listar apenas alguns de seus atributos - constitui-se pelo jogo e pelo jogo se expressa (2006,p.1).
}

Proporcionar experiências lúdicas pode ajudar o estudante a ter uma vivência muito mais significativa e verdadeira. Para que as experiências aconteçam dentro do espaço do museu, é preciso que o professor mediador esteja preparado para brincar, pois é dele que vai partir o jogo. Esse é mais um ponto importante na formação destes profissionais. O contato com a obra de arte, permite ao cego a possibilidade de viver outras realidades, desempenhar outros papéis, tornando-o mais curioso ao descobrir novas coisas, desvendando novas possibilidades. Por isso é importante que na sua formação o lúdico tenha seu devido espaço. Fortuna, ainda nos fala da parceria da escola com o museu: “(...) é possível conjugar aprender, ensinar com prazer através de atividades onde os objetivos educacionais são subordinados a vivência da alegria, curiosidade, socialização e reflexão - própria da ludicidade quanto da aprendizagem" (2006,p.4).

Para Ott (1997), ensinar dentro do espaço do museu é imprescindível para arte educação, pois no contato direto com a obra de arte é que se tem a verdadeira noção de arte como conhecimento. É no museu que diferentes culturas guardam suas coleções, relíquias, conquistas e inquietações surgidas ao longo da história. $\mathrm{O}$ autor completa que o museu pode

\footnotetext{
${ }^{9}$ www.museu.ufrgs.br/admin/artigos/arquivos/artigotaniafortuna.pdf, 19/07/2007, 10:11h.
} 
ser um grande laboratório onde através de experiências esse conhecimento pode ser vivenciado.

A mediação no museu de arte pode estimular as características investigadoras de seus visitantes, propondo relações reflexivas para que o fruidor volte ao espaço museológico. "Se o que atrai e torna o visitante do museu seu amante é a curiosidade, a questão é: como estimulá-la, acolhê-la, dar lugar para que se manifeste" (Fortuna 2006: p.10). Este é o desafio dos profissionais ligados à área. Ao levar o cego para o espaço do museu, tanto o professor quanto o mediador do museu apresentam outra forma de aprender. Os mediadores e professores devem saber envolver, ligar, e contextualizar os temas ou obras do museu.

Araujo identifica que:

Ao nos referirmos a outros canais sensoriais para o desenvolvimento dos esquemas
sensório-motores da criança cega, destacamos, dentre eles, o esquema tátil
percebido na extensão de todo o seu corpo e de seu desdobramento através das
sensações táteis-cinestésicas. (2000, p.05)

Neste caso o atendimento da pessoa cega no museu além de cumprir com os aspectos de cidadania também colaboram no processo de significação tátil, ampliando as possibilidades de subjetivação dos aspectos simbólicos. Desenvolver a capacidade lúdica da criança de modo geral é tarefa das instituições educativas, no caso da criança cega estes aspectos são fundamentais para ampliar sua comunicação com o mundo.

\section{As experiências desenvolvidas pelo projeto:}

Como já mencionado anteriormente, partimos de uma metodologia de pesquisa-ação, entendendo-a como uma metodologia que explora a relação entre o individual e o social na medida em que os indivíduos se constroem a partir destas relações. Ela, então, requer a participação das pessoas envolvidas, propiciando uma troca entre pesquisadores e participantes. Estes participantes cumprem a tarefa de avaliação das investigações, sendo então uma prática colaborativa. Ela também pode ser emancipatória sendo que através dos resultados dos processos de pesquisas, pode-se solucionar problemas sociais e encontrar outras possibilidades de agir. A pesquisa-ação estimula os processos críticos quando reflete sobre situações que necessitam de mudanças. Por fim ela (...) é um processo de aprendizado por meio do fazer - e aprendizado com os outros por intermédio de mudanças nos modos com que interagem em um mundo compartilhado socialmente" (Kemmis e Wilkinson: 2002,48). Neste sentido seguem as experiências desenvolvidas e algumas conclusões que chegamos com base nos relatos e vivencias com os materiais adaptados. 
O Núcleo de Arte Educação do MASC, que realiza a parte de informação e divulgação do acervo e das exposições temporárias, tem desenvolvido mediações quando recebem escolas e outros grupos. Mesmo sem experiências sistematizadas sobre esse processo, o NAEIMASC nos recebeu dando todo o apoio necessário para o desenvolvimento das nossas ações, desde a disponibilidade do espaço físico, acesso ao acervo e participação em todas as etapas do projeto.

Para que pudéssemos realizar novas experiências para aproximar o cego do museu o projeto contou com a colaboração de Geofilho Ferreira, um estudante de psicologia de 27 anos que perdeu a visão na adolescência. Vivemos em um mundo extremamente visual, onde somos bombardeados por imagens quase que o tempo todo. Em contato com alguém que é cego, percebemos que é possível "ver" não só com os olhos, mas também envolver outros sentidos como o olfato, a audição, o paladar e o tato.

Em uma primeira visita ao museu, Geofilho tocou nas obras do acervo que se encontram nos jardins internos do prédio do Centro Integrado de Cultura, onde se localiza o MASC. Essas obras foram escolhidas por se tratarem de esculturas não pontiagudas e de materiais com texturas que não ofereceriam nenhum perigo de arranhão ou corte ao estudante. A mediação foi feita por Márcia Lisboa Calrsson e Sérgio da Silva Prosdócimo, ambos arte educadores do Museu. As obras tocadas foram: "Esfinge" (1984), de Francisco de Paula Brennand (grés esmaltado 82 X 41 X 42); "Figura sentada" (1986), de Elke Hering (cimento 175 X 61 X 80); “Sem título” (1987), de Mario Avancini (granito 61 X 40 X 29); e “Integração" (1987), de Helena Montenegro (cimento 52 X 83 X 65).

Ao entrar em cada ambiente do jardim o mediador teve o cuidado de descrever como eram as plantas e pedras. E o fez por meio de diálogo constante com Geofilho que ia sentindo e ouvindo o barulho no chão e entendendo desta forma o espaço ao qual estava sendo inserido. Ao tocar nas esculturas verificamos que a maior dificuldade se deu quanto à identificação da obra de maior dimensão, pois, não foi possível para ele ter uma noção do total do objeto de arte. A escultura que Geo mais gostou foi a "Esfinge" de Brennand porque ela tem uma maior proximidade com o figurativo, apesar de ser uma obra um tanto quanto inusitada. Ela tem olhos, boca, números e símbolos, sendo que as outras obras são mais abstratas. Enfatizamos aqui as palavras de Geofilho: "Nesta visita, esta foi à obra que mais gostei de contemplar. Pude ter noção exata do tamanho e dimensão da obra. Quando comecei a tocá-la imaginei um cavalo; depois uma serpente, mas sabia que aquela obra não conservava as mesmas formas destes animais citados por mim. Depois que a Márcia disse que era a Esfinge, mito grego, fez sentido. Mas não significa que, mesmo que o autor tenha 
dado nome à obra, isso nos impeça de dar a nossa interpretação, de acordo com a nossa imaginação; pois, não existe interpretação pura, ela é singular às nossas experiências" (Depoimento registrado).

Em outra visita ao museu, Geofilho pode tocar em algumas obras da exposição $D e$ dentro pra fora, uma mostra do Centro de Artes - CEART/UDESC as quais o toque foi permitido previamente pelos organizadores, sendo que alguns dos trabalhos tinham caráter interativo. Com essas experiências constatou-se a importância do tamanho da matriz tátil para que o cego tenha compreensão tátil-cognitiva, com formas e linhas claras sem muitos detalhes e a função do mediador que é quem recebe os visitantes, além da acessibilidade fisíca do lugar.

A exposição Centenário Martinho de Haro foi escolhida para darmos continuidade às ações propostas pelo projeto. O motivo da escolha se deu primeiro por se tratar de um pintor catarinense com grande projeção nacional que retratou a cidade de Florianópolis como ninguém, portanto, com um forte caráter histórico. Segundo, por podermos desenvolver as matrizes táteis em obras que são do acervo do museu, para que sempre que possível estejam disponíveis a futuras visitas guiadas para o público com necessidades especiais.

Foram quatro as obras escolhidas a serem adaptadas para o alto-relevo: "A moça", 1975/80; "Cais de Florianópolis - Porto" sem data; "Lubricidade" sem data e "Sem título" 1992. O artista plástico Edmilson Vasconcelos foi o executor das matrizes táteis que são objetos que saem do plano bidimensional e podem de fato ser manuseados, com texturas que estimulam as sensações tácteis. Foram feitas também as etiquetas das obras e 20 catálogos em Braille, e através da parceria com a AAMABAS, o material foi impresso. O catalogo relata uma breve história da vida e obra do artista e os textos foram escritos juntamente com o NAE, sob a coordenação de Christiane Maria Castellan, o que deu maior autonomia ao cego durante a exposição.

As atividades relatadas acima comprovaram as muitas indagações que envolveram todo o projeto, Tojal (1999) chama a nossa atenção para ao fato de que o público cego é o que exige um maior número de adaptações em uma exposição, mas por outro lado também aponta para as possibilidades e inovações surgidas no que diz respeito às novas formas de apreensão e fruição do objeto. Sendo assim, a equipe que trabalha em um museu de arte e que acompanha as políticas inclusivas do seu tempo, além de fazer a inclusão deve ter consciência da contribuição que o público com necessidades especiais lhes impõe desafios, 
na medida em que tira esse profissional de uma posição de conforto e o faz repensar e ampliar o seu papel na sociedade.

\section{Considerações finais}

Quando pensamos na acessibilidade de cegos em museus de artes, sabemos das implicações e superações que envolvem esta questão, as atividades desenvolvidas até o momento nos deram uma mostra do que é possível ser feito. As matrizes táteis, o material em Braille, e o papel importantíssimo do mediador fazem toda a diferença, pois em uma sociedade dominada pela cultura visual torna-se imprescindível que o cego também tenha acesso e ela. O espaço museológico pode e deve abrir caminhos para este acesso, juntamente com um professor de artes que esteja comprometido com seu papel de educador inclusivo, saindo da comodidade da sala de aula para proporcionar a estes estudantes uma integração com os demais, bem como com o patrimônio artístico cultural ali contido.

Dewey (1974) em seu livro “Arte como Experiência", fala da idéia de experiência, dando o exemplo de uma pedra que rola de cima de uma montanha. O objetivo da pedra é chegar lá em baixo, mas para chegar, ela passa por uma série de experiências em um movimento contínuo. E quanto mais ela ficar marcada pelo caminho, mais ela revela de suas experiências, no contato com as outras pedras, com o barro, com o mato, com as flores. A qualidade estética desta experiência se dá justamente na integração do que ela trouxe consigo por todo o caminho, tornando-se uma unidade diferente daquela antes de percorrê-lo. Falo deste exemplo de Dewey pensando em todo o caminho percorrido pelo projeto até aqui. Muitas já foram às experiências agregadas ao longo do nosso caminho, mas também sabemos que ainda não chegamos ao fim da montanha pelo contrário apenas começamos a decida, no caminho que estamos percorrendo para promover a acessibilidade ao cego.

Desenvolvemos ao longo do projeto um conjunto de características que as matrizes táteis precisam ter para cumprir seu papel. Assim, destacamos aspectos do material que precisa ser lavável e de material não tóxico e de estrutura forte. Precisa ter uma dimensão que possibilite um tateamento global pelo cego. Ainda a matriz tátil não necessita de uma reprodução global da obra de arte. Para ser tatilmente eficaz ela precisa ser uma síntese do objeto artístico, mostrando suas principais características de contraste entre os planos diferenciados. Acreditamos que estes resultados poderão servir de base para a criação e experimentação tátil de novas matrizes com públicos cegos em museus de arte, iniciando neste caso uma nova proposta do projeto. 


\section{Referencial Bibliográfico:}

ARAUJO, Sonia Maria Dutra de. O jogo simbólico numa proposta pedagógica para o deficiente visual. Disponivel em www.clicktoconvert.com acessado em maio de 2008. BARROS, de Armando Martins. "Quando a cegueira guia o olhar: notas sobre as práticas educativas inclusivas". Universidade Federal Fluminense - UFF.

DEWEY, John. “A Arte Como Experiência”. São Paulo: Abril SA, 1974. FORTUNA, Tânia Ramos. “O Museu em Jogo”. Revista Museu: 2006. KEMMIS, Stephen; WILKINSON, Mervyn. "A pesquisa-ação participativa e o estudo da prática". In: PEREIRA, Júlio Emílio Diniz; ZEICHNER, Kenneth M (orgs.). “A pesquisa na formação e no trabalho docente". Belo Horizonte: Ed. Autêntica, 2002. LEONTIEV, Aléxis. “O Desenvolvimento do Psiquismo”. São Paulo: Ed. Centauro, 2004. MENDES, Eunicéia Gonçalvez. “A radicalização do debate sobre inclusão escolar no Brasil”. Revista Brasileira De Educação. Set, dez de 2006.

OTT, Robert William. "Ensinando Crítica nos Museus” in BARBOSA, Ana Mae (org.). “Arte-Educação: leitura no subsolo”. São Paulo: Cortez, 1997. PERRENOUD, Philipp. "Formar professores em contextos sociais em mudança”. Universidade de Genebre, Caximbu, 1999.

TOJAL, Amanda Pinto da Fonseca. "Museu de arte e público especial”. Dissertação de Mestrado. ECA - USP, 1999.

VASINER, Jaan e VEER, René Van Der."Vygotsky, uma síntese”. São Paulo: Ed. Loyola, 1996. 